\title{
FILOSOFÍA DEL DERECHO EN LATINOAMÉRICA *
}

\author{
Rodolfo Vázquez \\ ITAM (México)
}

RESUMEN. Este artículo intenta organizar y sintetizar el pensamiento iusfilosófico latinoamericano contemporáneo en algunos países representativos del continente (Colombia, Chile, Costa Rica, México, Perú, Uruguay y Venezuela), de manera que dé cuenta de la variedad y complejidad de autores y escuelas, con las peculiaridades propias de la región. La agenda temática abarca desde la teoría del derecho y la argumentación jurídica, hasta problemas relacionados con la teoría de la justicia: derechos sociales, multiculturalidad, pobreza, desigualdad, transparencia y rendición de cuentas, entre otros.

Palabras clave: Latinoamérica, filosofía del derecho, argumentación jurídica, teoría de la justicia.

ABSTRACT. This article attempts to organize and synthesize some representative Latin American countries' contemporary legal-philosophical thought (Chile, Colombia, Costa Rica, Mexico, Peru, Uruguay, and Venezuela). I attempt to do so in such a way as to portray the complexity and variety of authors and schools of thought involved, all the while accounting for regional particularities. The thematic agenda covers issues ranging from theory of law and legal argumentative theories to problems of justice proper: social rights, multiculturalism, poverty, inequality, transparency and accountability, among others.

Keywords: Latin America, philosophy of law, legal argumentation, theories of justice.

\footnotetext{
* Fecha de recepción: 5 de septiembre de 2011. Fecha de aceptación: 5 octubre de 2011.
} 


\section{1 contexto histórico y político-cultural latinoamericano en el que es posible hablar de una «normalización» de la filosofía en general, y de la filosofía ju- rídica en particular - para usar la expresión del filósofo F. ROMERO- no ha sido otro sino el de la modernidad. Pero, ¿cuál modernidad? Decía O. PAZ, en un esfuerzo de síntesis:}

[Latinoamérica] había nacido como una proyección de la visión universal de la monarquía hispánica, que albergaba una pluralidad de naciones y que se sustentaba en una filosofía: el neotomismo. Esa construcción política y la filosofía que la justificaba fueron disipadas por la historia, pero los cimientos, la fundación — la lengua, la cultura, las creencias básicas - resistieron a los cambios. Después concebimos un proyecto no menos universal: la modernidad republicana y democrática. La realización de ese proyecto exigía una crítica radical de nuestro pasado y de nuestra cultura. Tras muchas vicisitudes hemos penetrado en el mundo moderno. Vivimos un periodo de transición e ignoro cuál será el resultado de este gran proceso de cambio. En todo caso, puedo decir que nuestra suerte será la de la modernidad... y la modernidad está en crisis ${ }^{1}$.

PAZ escribía este texto en 1991. Daba inicio una década de grandes esperanzas para Latinoamérica — después de las terribles dictaduras militares y de la llamada «década perdida» de los ochenta- por lo que respecta a la instrumentación efectiva de un sistema de justicia internacional en los ámbitos nacionales y la tan ansiada consolidación democrática. Una década de transición hacia una modernidad, por decir lo menos, incierta. Con todo, el peso del pasado no era algo que podía obviarse sólo con buenos propósitos. Resulta ya un lugar común afirmar que América Latina ha sido una rezagada con relación a las tres revoluciones científico-tecnológicas modernas: se educa en el dogmatismo de la contrarreforma sin haber conocido la reforma; importa una concepción liberal e ilustrada del Estado sin una burguesía que la haya instrumentado; e incorpora el discurso de la globalización ignorando las profundas desigualdades ancestrales de nuestros pueblos. El «cesarismo», el clientelismo y la anomia generalizada seguirían siendo las características distintivas de nuestra mentalidad colectiva latinoamericana:

Las normas —afirmaba M. KAPLAN— son percibidas como inválidas o ineficaces, lo legal como ilegítimo, lo ilegal como razonable y necesario. La política del sacrificio, del esfuerzo, del trabajo, cede el lugar a la ética fundada en la especulación, la esperanza de ganancia rápida, la reposición del capital en poco tiempo, el consumismo ficticio respecto al estado real de la economía nacional. La delincuencia es así generada, no sólo por las estructuras económicas y sociales, sino por ciertos rasgos de mentalidad colectiva y de la cultura predominante, que son creados y desarrollados históricamente, y en la interdependencia con aquéllas ${ }^{2}$.

La última ola democratizadora hizo pensar a muchos que había llegado la hora de América Latina para transitar - como ya se estaba operando en Europa desde hacía muchos años- de un Estado legislativo hacia un Estado constitucional de derecho. A partir de la década de los noventa asistimos en América Latina, y México no es la excepción, a un reposicionamiento de la democracia constitucional. Este consenso en torno al constitucionalismo democrático, como explica el constitucionalista chileno

\footnotetext{
1 O. PAz, Huellas del peregrino, México, Fondo de Cultura Económica, 2010, 209-210.

2 M. KAPLAN, Estado y globalizaciòn, México, UNAM, 2002, 364.
} 
J. Couso, se operó tanto desde la izquierda como desde la derecha. Por el sector de la izquierda, la ola dictatorial de los años precedentes, traducida en términos de tortura, desapariciones, ejecuciones extrajudiciales y otras violaciones a los derechos humanos, llevó a este sector a valorar instituciones constitucionales como el babeas corpus o el debido proceso. Asimismo, la caída de los socialismos reales planteó a la izquierda la necesidad de promover los derechos fundamentales, y aceptar atrincherarlos en las cartas constitucionales, como un elemento necesario de cualquier régimen político razonable. Por el sector de la derecha, el pragmatismo económico les condujo a la convicción de que «sin un estado de derecho sólido que estableciera derechos de propiedad claros, un poder judicial independiente y una fuerza pública bien organizada, los países más atrasados no alcanzarán el desarrollo económico» ${ }^{3}$. Los sectores más conservadores comenzaron a valorar las contenciones propias incluidas en los diseños constitucionales. De esta manera, sea por la vía dogmática o por la vía orgánica, la democracia constitucional se presentaba como la única alternativa posible para alcanzar los consensos necesarios de gobernabilidad.

Esta ola constitucional, propia de las democracias representativas, comenzó a tomar cuerpo a partir de varios ejes de análisis y de demandas sociales: 1) la construcción de un modelo de Estado de derecho caracterizado por el reconocimiento y la efectividad del más amplio elenco de derechos humanos, que incluyera los derechos civiles y políticos, así como los económicos, sociales, culturales y de tercera generación; 2) el atrincheramiento de los mismos en la norma suprema constitucional reforzada por los instrumentos propios del derecho internacional de los derechos humanos; 3) la organización y preparación de un cuerpo judicial progresista, independiente e imparcial, que garantizara la judiciabilidad de los derechos, especialmente de los sociales, con deferencia — que no subordinación- hacia los órganos de representación popular; 4) la construcción de una democracia incluyente que abriera los canales adecuados para el reconocimiento de las minorías étnicas, los grupos vulnerables y los colectivos mayoritarios históricamente excluidos; 5) el empoderamiento de estos grupos a través de mecanismos procesales reconocidos legal y judicialmente, como el habeas corpus, la tutela, el amparo y las acciones colectivas, y 6) todo lo anterior, con el fin de construir una sociedad más homogénea y plural a partir de la implementación de políticas públicas que hicieran valer el principio de igualdad para tutelar las diferencias y reducir las desigualdades económicas y materiales.

Existen razones para pensar que en América Latina este proyecto de democracia constitucional ha cumplido escasamente con las promesas anunciadas. Desde fines de los noventa y hasta la fecha se ha percibido en la región lo que algunos han denominado una «epidemia de poderes especiales». Todo indica, como bien decía E. ZAFFARONI, que lejos de enfilarnos desde un Estado legal de derecho a uno constitucional, involucionamos, de nueva cuenta, hacia un Estado «decretal» de derecho ${ }^{4}$. Lejos de consolidar una cultura de la legalidad robusta en el marco de un Estado democrático y social de derecho, nos encaminamos hacia una cultura de la (i)legalidad o, en términos

3 J. Couso, «Los desafíos de la democracia constitucional en América Latina: entre la tentación populista y la utopía neoconstitucional», en Anuario de Derechos Humanos, Universidad de Chile, 2010, 38.

4 E. R. ZAFFARONI, «Dimensión política de un poder judicial democrático», en M. CARBONELL, H. FIX-FieRRO y R. VÁzQUeZ (comps.), Jueces y derecho. Problemas contemporáneos, México, Porrúa-UNAM, 2004, 120. 
de G. O'Donnell, a un un(rule) of law en donde lo que priva es una «ciudadanía de baja intensidad»:

Quiero con esto decir que todos tienen, al menos en principio, los derechos políticos que corresponden a un régimen democrático, pero a muchos les son negados derechos sociales básicos, como lo sugiere la extensión de la pobreza y la desigualdad [...] A estas personas se les niegan también básicos derechos civiles: no gozan de protección ante la violencia provincial ni ante diversas formas de violencia privada, se les niega el fácil y respetuoso acceso a las instituciones del estado y a los tribunales; sus domicilios pueden ser allanados arbitrariamente, y, en general, son forzados a llevar una vida que no sólo es de pobreza sino también de sistemática humillación y miedo a la violencia [...] Estas personas, a las que llamaré el sector popular, no son sólo materialmente pobres, son también legalmente pobres 5 .

El sociólogo chileno J. LARRAÍn ha expresado esta situación con una frase intimista y contundente: vivimos en el «síndrome de desesperanza aprendida» ${ }^{6}$. No se trata sólo de desplazados, sino de un número creciente de individuos que han perdido la ilusión de un futuro y les resulta insostenible la persistencia en un clima de incontrolable inseguridad. Tal parece que un buen sector de nuestras poblaciones vive en una dinámica que el jusfilósofo brasileño Ó. VILHENA ha caracterizado con los términos de «invisibilidad de los extremadamente pobres», «demonización de los que cuestionan el sistema» e «inmunidad de los privilegiados», o de los detentadores fácticos del poder ${ }^{7}$. Trilogía que se corresponde con otra, no menos dramática: la corrupción, ineficiencia e impunidad de nuestros gobernantes. Por ello, tiene razón E. GARZÓN VALDÉS cuando critica a un buen número de estudiosos latinoamericanos por vivir bajo el «velo de la ilusión» y disimular nuestros fracasos bajo eufemismos como el que encierra la expresión «transición a la democracia», que sólo justifica el «retraso» o el «apartamiento de la meta proclamada»; o bien, vivir bajo la ilusión de un «Estado de derecho» cuando existe una distancia abismal entre las reglas formales y las reglas vividas:

Hablar de la vigencia del rule of law es, en la mayoría de los países de América Latina, desfigurar la realidad jurídica y despistar a quien quiera interesarse por las normas que rigen el comportamiento de gobernantes y gobernados en amplios campos de la vida social. A quien tenga predilección por las citas literarias, me permito recordarle la siguiente frase de un personaje de A. CARPENTIER: «Como decimos allá, "la teoría siempre se jode en la práctica" y "jefe con cojones no se guía por papelitos"» ${ }^{8}$.

Los signos que se manifiestan actualmente en buena parte de los países de la región no invitan, ciertamente, al optimismo: el antecedente del fujimorismo y los actos de corrupción y nepotismo de los sucesivos gobiernos en Perú; el populismo autoritario que se percibe en los gobiernos de Nicaragua, Venezuela, Ecuador, Paraguay y Bolivia; el abusivo uso de los decretos de necesidad y urgencia, y la ineficiencia e impunidad de los gobiernos argentinos desde Menem a la fecha; la violencia generalizada por la

5 G. O’DonnelL, «Democracia, desarrollo humano y derechos humanos», en G. O'Donnell, O. IAZZEETTA y J. Vargas Cullell (eds.), Democracia, desarrollo bumano y ciudadanía, Rosario, Homo Sapiens, 2003, 91.

${ }^{6}$ J. LARRAín, Identidad chilena, Santiago de Chile, LOM Ediciones, 2001, 90, citado por E. GARZÓN VALDÉs, «Las élites latinoamericanas», en E. GARZÓn VALDÉs, J. MugueRZA y T. R. MurPhy (comps.), Democracia y cultura política, Las Palmas de Gran Canaria, Fundación Mapfre Guarteme, 2009.

7 Vid. O. VilHENA, «La desigualdad y la subversión del Estado de Derecho», en Revista Internacional de Derechos Humanos, núm. 6, año 4, 2007, 29 y ss.

8 E. GARZÓN VALDÉS, Las élites latinoamericanas, 205-243. 
delincuencia organizada y las políticas represivas — que no preventivas- en Colombia y México; la pobreza endémica de buena parte de los países centroamericanos y del Caribe; la humillante desigualdad económico-social en toda la región, pero de manera más acuciante en países emergentes como Chile y Brasil ${ }^{9}$.

Quizás sea el momento, como dice R. GARGARELLA, de pensar a fondo en el rediseño de una maquinaria institucional que ya se percibe como «exhausta». Vale la pena citar in extenso un texto suyo escrito recientemente con ocasión del bicentenario de la independencia en varios países de la región:

Después de más de doscientos años de vida del constitucionalismo moderno, entendido éste a partir de sus rasgos básicos - la adopción de una declaración de derechos y de un sistema de «frenos y contrapesos»— no puede decirse del mismo que su funcionamiento haya sido exitoso, particularmente en una mayoría de países de América. Tal mayoría de países sigue viéndose afectada por sistemas políticamente inestables y económicamente muy desiguales; en donde las violaciones de derechos humanos son un hecho habitual; las ramas políticas del gobierno tienden a funcionar con independencia de cualquier reclamo ciudadano, mientras se encargan de moldear normas a medida de intereses privados; los tribunales aparecen como órganos de difícil acceso público, que tienden a decidir en favor de los poderosos, criminalizando a quienes protestan; y en donde el debate público (tanto en las campañas electorales como, especialmente, en los periodos que transcurren entre una elección y otra) destaca por la pobreza de su contenido. [...] Según entiendo, la gravedad de las deficiencias institucionales en juego nos obligan a dejar de lado la idea según la cual lo que se requiere es «perfeccionar» $\mathrm{o}$ «pulir» algunos aspectos de dicho esquema. [...] existe urgencia por repensar las causas de lo que es, en definitiva, un fracaso institucional con consecuencias ya trágicas ${ }^{10}$.

Resulta notable que en este panorama poco alentador se haya desarrollado en algunos países de la región, desde mediados del siglo pasado, una filosofía del derecho que, sobre todo, ha tenido el mérito de traducir los grandes temas y debates de los países más avanzados, y haberlos sabido incorporar a las demandas y exigencias propias de la región. Con ello se ha construido, digámoslo así, una agenda de problemas latinoamericanos, que han ocupado la atención de nuestros principales jusfilósofos: una adecuada teoría de las normas y de los ordenamientos jurídicos a partir de modelos clásicos y de la más reciente incorporación del llamado neoconstitucionalismo; los análisis en torno a la moderna teoría de la argumentación y su fructífera aplicación en sede judicial; una sólida teoría de la justicia en diálogo recurrente con otras disciplinas prácticas como la política y la economía. Sobre una teoría de la justicia pensemos, por ejemplo, en el debate en torno a los derechos humanos, y de manera especial, sobre los derechos sociales y su necesaria judicialización; las reflexiones sobre los problemas de una región caracterizada por su multiculturalidad y el lugar de las poblaciones in-

9 El primer Informe regional sobre desarrollo bumano para América Latina y el Caribe (2010), elaborado por el PNUD, arroja cifras muy preocupantes: 10 de los 15 países más desiguales del mundo se encuentran en América Latina y el Caribe. De acuerdo con el coeficiente de Gini del ingreso de la región —el indicador más usado para medir la desigualdad-, es un 65 por 100 más elevado que el de los países de ingreso alto, un 36 por 100 más alto que el de los países del este asiático y un 18 por 100 más alto que el promedio de África subsahariana. Mención aparte, y como islotes en una indecencia generalizada, merecen Costa Rica y Uruguay.

10 R. Gargarella, «Una maquinaria exhausta. Constitucionalismo y alienación legal en América», en Isonomía, núm. 33, México, Instituto Tecnológico Autónomo de México-Escuela Libre de Derecho, octubre 2010, 7-8. 
dígenas en un entorno globalizador; las propuestas de construcción de un Estado democrático y social de derecho en sociedades profundamente polarizadas en términos de pobreza y desigualdad; o bien, los estudios sobre la exigencia de responsabilidad a nuestros gobernantes - transparencia, rendición de cuentas, eficiencia, control de la impunidad - y la urgente necesidad de construir un tejido social cohesionado con una ciudadanía crítica y activa. Éstos y otros tantos problemas han obligado, también, al replanteamiento de la enseñanza de nuestra disciplina en las aulas universitarias y la necesaria renovación de nuestra planta de docentes y de investigadores. Es ésta una tarea ardua que ha encontrado innumerables resistencias, sobre todo si pensamos en el tradicional conservadurismo que caracteriza a nuestras facultades de derecho, pero, indudablemente, es un pendiente impostergable.

No ha sido una tarea sencilla intentar organizar y sintetizar el pensamiento jusfilosófico latinoamericano desde el río Bravo hasta la Patagonia de manera que dé cuenta de la variedad y complejidad de autores y escuelas, con las peculiaridades propias de la región, en su conjunto, y de cada uno de los países. Una restricción impuesta para este ensayo es la de no abordar dos países, Argentina y Brasil. No cabe duda que la relevancia de la producción jusfilosófica argentina y las características propias de la historia y cultura lusoamericanas son razones más que suficientes para justificar un tratamiento especial y por separado.

Otra restricción tiene que ver con la temporalidad. Si bien es posible rastrear los orígenes de dos de las teorías más recurrentes en los debates jusfilosóficos modernos —el jusnaturalismo y el positivismo jurídico- desde los movimientos independentistas en la región en los inicios del siglo XIX, no es sino hasta la década de los años cuarenta del siglo XX que es posible hablar de una «normalización» de la filosofía jurídica. Lo mismo que ROMERO aplica a los «fundadores» de la filosofía latinoamericana -A. Caso, J. Vasconcelos, C. Vaz Ferreira, J. Ingenieros, A. Korn, E. Molina, A. DEUSTÚA, R. DE FARÍAS BRITO— es posible extenderlo a nuestra disciplina: se adquiere una presencia y una sistematización, que no había tenido antes, y se pasa de una «improvisación fácil» hacia un trabajo «metódico y riguroso» realizado sobre la base de una información directa respecto de la producción filosófica de los países europeos. Entre los jusfilósofos cabe mencionar a C. Cossio, L. RECASÉNS SiCHES, J. LLAMBíAs DE Acevedo, E. García Máynez, R. Pizani, M. Reale, A. Gioja, L. E. Nieto Arteta, J. Millas y F. Miró Quesada.

No todos los países de la región han recibido igual tratamiento en este ensayo, en buena medida debido a la escasa contribución a la disciplina o a la reiteración de problemas y debates ya suficientemente desarrollados en otras latitudes y trasladados sin un aparato crítico adecuado. Con todo, se ofrece un conjunto representativo que permite dar una idea bastante objetiva del pensamiento y la producción latinoamericanos. El orden en la exposición de cada país sigue un criterio estrictamente alfabético ${ }^{11}$.

11 Para la presentación de los países incluidos en este ensayo he incorporado de manera sintética, y adaptada a las exigencias de este trabajo, las ideas y comentarios que he recibido por escrito de P. RUIZ TAGLE (Chile), M. Salas (Costa Rica), L. García Jaramillo (Colombia), D. Sobrevilla (Perú), Ó. Sarlo (Uruguay) y J. BARRAGÁn (Venezuela). A todos ellos les agradezco su invaluable colaboración. 


\section{COLOMBIA}

La fundación del Instituto de Filosofía y Letras de la Facultad de Derecho de la Universidad Nacional, en 1946, se considera como el momento de «normalización» de la filosofía en Colombia. Dos obras marcaron decisivamente el inicio de la filosofía iusfilosófica moderna: Lógica, fenomenología y formalismo jurídico, de L. E. NIETO ARTETA, considerado el primer difusor de la teoría pura de KELSEN en Colombia, y El ambiente axiológico de la teoría pura del derecho, de R. CARRILLO. Ambas obras contribuyeron determinantemente a romper con el pasado filosófico neo-tomista que imperaba hasta ese entonces desde el proyecto ideológico plasmado en la Constitución regeneracionista de NúÑEZ y CARO. Otras figuras importantes en la normalización de la filosofía jurídica en Colombia fueron C. BETANCUR, fundador en 1951 de la que es considerada ahora la principal revista filosófica colombiana: Ideas y Valores; el jurista J. VÉLEZ SÁENZ, cuya importancia en la rama analítica es altamente apreciada, y A. NARANJo Villegas, quien estudió filosofía con M. García MORENTE y F. ROMERO.

La discusión entre jusnaturalistas y juspositivistas, como en gran parte de los países de habla hispana, ocupó un lugar central en los debates sobre la naturaleza del derecho. El positivismo, en particular en su versión kelseniana, ejerció un influjo que aún enseña sus consecuencias en el diseño de los programas de estudio en todo el país. De igual manera, el iusnaturalismo ejerció una influencia determinante en los temas y los contenidos de la reflexión jusfilosófica. Debido a que el núcleo del iusnaturalismo afirma que ciertos principios de derecho natural —inmutables y eternos- existen por encima de las leyes humanas, resultó favorable para articular una concepción basada en que esos principios eran aquellos defendidos por la fe católica. En Colombia se debió esperar hasta la promulgación de una Constitución liberal laica en 1991, y en particular a la instauración de un tribunal que garantizara los derechos allí consagrados, para que se decidiera sobre temas hasta entonces ideológicamente censurados como el aborto, la eutanasia, los derechos para las parejas del mismo sexo y la implementación de políticas de discriminación positiva.

El realismo jurídico norteamericano se ha estudiado más que el escandinavo, con excepción de A. Ross. Otras tendencias han sido la propuesta jurídico-democrática de HABERMAS y su teoría discursiva que se conoce en el país gracias a G. HOYOS VÁzQUEZ y su discípulo O. MEJÍA QUINTANA, autor este último de la primera publicación sobre la filosofía jurídica del autor germano. Desde entonces MejÍA QuinTANA ha investigado sobre temas de filosofía política y crítica a la jurisprudencia constitucional, como puede apreciarse en sus libros Derecho, legitimidad y democracia deliberativa y Teoría politica, democracia radical y filosofía del derecho. Por su parte, Hoyos publicó, junto con Á. URIBE, la compilación Convergencia entre ética y política.

El cambio en el paradigma interpretativo del derecho de DwORKIN, sus críticas al liberalismo político mediante su propuesta del liberalismo igualitario y sus tesis sobre los principios generales del derecho han sido particularmente relevantes en Colombia fundamentalmente desde 1991. R. ARANGO ha ejercido una influencia determinante en la recepción curricular y doctrinaria de las teorías de DwORKIN, tanto sus tesis jurídicas ligadas a la interpretación del derecho, como las tesis filosófico-políticas relacionadas 
con las concepciones no-agregativas de la democracia y los derechos como cartas de triunfo frente al poder, lo que puede apreciarse en sus libros $i$ Hay respuestas correctas en el derecho? y Derechos humanos como límites a la democracia.

La teoría feminista del derecho ha encontrado un campo de fructífero cultivo en la Universidad de los Andes a través de publicaciones como la obra colectiva coordinada por C. MotTA y M. SÁeZ, de la Red Alas, La mirada de los jueces. Género en la jurisprudencia latinoamericana, y también, en buena medida, debido al trabajo de ONGs que reivindican derechos de igualdad para las mujeres. Los Estudios Críticos del Derecho (en particular KENNEDY) se han desarrollado en los trabajos de D. LÓPEZ MEDINA. Este investigador es uno de los teóricos del derecho más influyentes en la actualidad. Primero publicó sobre temas de filosofía del derecho en sentido estricto, ligados con la filosofía de PLATÓN, y recientemente, en sus libros El derecho de los jueces y La letra y el espiritu de la ley, ha trabajado sobre la teoría del precedente, los problemas ligados con los trasplantes jurídicos y ha señalado direcciones en torno a la discusión sobre la interpretación jurídica y sus métodos.

La interpretación jurídica, y en particular la interpretación constitucional, es uno de los temas cardinales en la agenda de trabajo iusteórico. Es abundante la producción local sobre la teoría de la argumentación jurídica de ALEXY, la cual se conoce gracias a la docencia y la producción intelectual de R. ARANGO —en su libro El concepto de derechos sociales fundamentales, con prólogo del propio ALEXY-, C. BERNAL PuLIDO y G. LOPERA, así como a las traducciones de L. VILLAR BORDA. El neoconstitucionalismo no sólo ha sido influyente sino que se han hecho aportes al canon trasnacional desde la doctrina y la jurisprudencia colombianas. Los trabajos de BERNAL PULIDO, primero desde el derecho constitucional de raigambre alexyana en El principio de proporcionalidad y los derechos fundamentales, hasta los más recientes, en torno a la filosofía del lenguaje, en El neoconstitucionalismo y la normatividad del derecho, han contribuido a configurar la naciente agenda de investigación en los terrenos de la teoría constitucional y la filosofía del derecho en sentido lato.

Se ha estudiado también la obra de Toulmin, Perelman, MacCormick, Aarnio, PeCZENIK y ATIENZA; la hermenéutica, específicamente en el sentido técnico de la modernidad a partir del siglo XIX (particularmente GADAMER) y la tópica jurídica de VIEHWEG. R. UPRIMY YEPES y A. ABEL RODRíGUEZ publicaron el opúsculo Interpretación judicial, en el cual se aborda el clásico problema del ámbito de la interpretación judicial, su práctica y sus límites, así como las principales teorías de la interpretación jurídica.

La teoría de los campos sociales de BOURDIEU ha permitido realizar interesantes articulaciones entre el discurso jurídico y el sociológico. Los estudios sobre la normatividad y las necesidades sociales desde distintos ámbitos como el poder judicial, la débil democracia, los déficits de representación, la teoría constitucional, por ejemplo, han recibido atención rigurosa desde hace algunos años, especialmente por UPRIMY, C. RODRíGUeZ y M. GARCÍA VILLEGAS. La obra colectiva El caleidoscopio de las justicias en Colombia, que García Villegas coordinó con BoAventura de Sousa, así como Jueces sin Estado y su más reciente Sociología y crítica del derecho constituyen sin duda una de las aportaciones más significativas al estado del arte.

La inclinación hacia la filosofía moral y política en Colombia constituye un pronto reflejo de los desarrollos que esta rama ha mostrado en otros países iberoamericanos 
que a su vez se corresponde con el resurgimiento del pensamiento político global por la obra de RAWLS. Un referente sobre la importancia de la teoría rawlsiana en la academia local lo constituyen las actividades realizadas con motivo de su fallecimiento, entre los que cabe destacar el trabajo monográfico editado por L. GARCíA JARAMILLO, John B. Rawls: El hombre y su legado intelectual, y en el cual se reúnen contribuciones de su discípulo y profesor asistente, Th. Pogge, su colega M. Nussbaum, así como de los principales expertos colombianos: O. Mejía Quintana, F. Cortés Rodas y D. IgNACIO GRUESO. Dentro de las concepciones normativas de la democracia cabe destacar los análisis sobre la concepción deliberativista de la misma y la importancia de las virtudes cívicas. En la obra colectiva editada por A. HERNÁNDEZ, Republicanismo contemporáneo. Igualdad, democracia deliberativa y ciudadanía, se encuentran varios textos sobre el tema.

Por último, la propia realidad del Estado colombiano ha propiciado diversos tipos de investigaciones, tales como lo relativo a lo multiétnico y pluricultural, pero en particular la consagración constitucional de los derechos de las poblaciones indígenas y su garantía por parte de la Corte Constitucional. Se distinguen los trabajos de D. BONILLA, La constitución multicultural, y Á. URIBE, Petróleo, economía y cultura. El caso U'wa, sobre los derechos culturalmente diferenciados.

\section{COSTA RICA}

En un tono categórico y crítico, no carente de realismo, M. SALAS sostiene que «en Costa Rica - y me temo que en buena medida en Centroamérica — no existe realmente filosofía del derecho. [...] A tal extremo se ha llegado que, en muchas universidades, la asignatura ya se suprimió; es decir, forma parte de anaqueles históricos y de proyectos curriculares fallidos, o no existe del todo». El desencanto de estas frases -más significativo proviniendo de uno de los países emblemáticos de la zona por su reconocida estabilidad social y democrática - no debe impedirnos destacar el trabajo personal y la contribución académica de figuras como E. P. HABA y, en generaciones más jóvenes, la del mismo M. Salas y G. González Solano.

HABA, de origen uruguayo, comienza una brillante carrera en Europa y desde 1978 se incorpora como catedrático de Filosofía del Derecho en la Universidad de Costa Rica hasta su retiro en 2006. Su pensamiento se inserta en lo que él mismo califica como una concepción crítico-realista o heurístico-negativa del derecho y de la teoría social en general. Dicha concepción, más que un conjunto de postulados teoréticos (por ejemplo, escepticismo epistemológico, orientación analítica, individualismo empírico) se caracteriza por una actitud intelectual frente a los problemas del conocimiento. Una lectura atenta de sus obras, entre las que cabe destacar La idea del totalitarismo y la libertad individual, Tratado básico de derechos humanos, pedagogismo y «mala fe», El espejismo de la interpretación literal y Metodología jurídica irreverente, revelará su especial inclinación mental por lo que él denomina «cuestiones de grado». El leitmotiv es, esencialmente, una preocupación por evidenciar y desarticular los vicios de razonamiento en que se incurre usualmente cuando se examinan temas de tipo social, jurídico, político y sociológico. Dentro de los vicios más criticados y combatidos en sus libros están el llamado «síndrome normativista de los juristas», las falsas generali- 
zaciones o «falacia del todo», la «concepción misionera de las ciencias sociales» y las «falacias de falsa oposición».

Las investigaciones de M. SALAS, profesor en la Universidad de Costa Rica, se despliegan en tres campos diferentes, pero relacionados entre sí: la filosofía del derecho, el derecho penal y la epistemología de las ciencias sociales. Sus trabajos se debaten, por un lado, con la idea de que algunos fenómenos sociales y jurídicos pueden (deben) ser sometidos a criterios de racionalidad y argumentación (racionalismo crítico), y, por otro lado, con la desalentadora comprobación de que justamente esos criterios de racionalidad, aun cuando se elaboren adecuadamente en la metateoría del derecho o de la teoría social, tienen escasísimas o nulas posibilidades de implementación en la praxis vital de las relaciones sociales y jurídicas en general (People Skepticism). Las instituciones jurídicas, y en particular los discursos jurídicos que versan sobre esas instituciones - no importa si es en el campo legislativo, judicial o, propiamente, en la teoría académica, o sea, en la dogmática jurídica que se elabora en las facultades de derecho-, juegan, según SALAS, básicamente el papel de legitimaciones simbólicas de la acción humana.

G. GONZÁlez SOLANO, también profesor en la Universidad de Costa Rica, por su parte, se autodefine como un «científico cognitivo», con una fuerte influencia de lo que, genéricamente, se podría llamar, filosofía analítica. Actualmente, sus investigaciones filosóficas se orientan hacia el estudio de la semiótica y la lógica (formal y no formal) de los discursos jurídicos, mediante los cuales quiere describir los procesos interpretativos, deductivos, abductivos y heurísticos llevados a cabo por los abogados y los jueces. El propio GonZÁlez SOLANO estima que sus investigaciones se ubican en lo que él llama: la etapa post-morrisiana, no creyendo, por ende, en naturalezas jurídicas innatas, ni esencias, ni paleosimbolismos, ni conceptualismos. Su propósito es hacer explícitos los procesos de dudosa procedencia y validez cognitiva en el campo jurídico, con la finalidad de implementar bases éticas y científicas para su optimización, pero sin guardar esperanza algunas de que ellas sean adoptadas o seguidas en la práctica.

\section{CHILE}

Acorde con las tendencias imperantes fuera de las fronteras chilenas, durante la década de los años treinta fue posible presenciar cómo el positivismo jurídico —en un ambiente fuertemente comprometido con las tesis iusnaturalistas- llegaba a las aulas y demás espacios de discusión, extendiendo su influencia en los intelectuales, filósofos y juristas chilenos. Así, por ejemplo, se destaca el valioso aporte del filósofo J. MiLLAS (1917-1982), quien en la filosofía jurídica podría enmarcarse dentro de la tendencia del formalismo axiológico y un pensamiento cercano al socialismo democrático. Si bien recibe influencia kelseniana, afirma que el fundamento último del derecho es el poder social que lo establece; se preocupa del estudio de las normas, especialmente de los valores jurídicos y de la naturaleza del derecho, llegando a identificar como el único valor a la seguridad jurídica. Quizás producto del contexto histórico que vive el país y de su recelo por las influencias de la ideología y de la politización de la academia, MiLlas identifica tal valor con lo que es conocido como el Estado de derecho. En 1960 se publica su libro Filosofía del derecho, que refleja su incesante estudio en esta disciplina. Su 
aporte se materializa también en la defensa de la universidad chilena. Así lo expresa de manera clara e incisiva en 1981, en su conferencia «Análisis de la universidad actual», que en forma dramática denomina «universidad vigilada» frente a la intervención militar de la que era víctima en los años de dictadura pinochetista (1973-1990).

Ya iniciada la segunda mitad del siglo XX es posible presenciar en la historia chilena la llegada de nuevas corrientes absolutamente reformadoras de las tendencias imperantes. Al respecto, cabe destacar el inmenso legado del profesor E. NOVOA MONREAL (1916-2007) en la década de los sesenta e inicios de los setenta, quien paralelamente a su legado político como asesor jurídico del gobierno de Salvador Allende, divulgó su pensamiento jurídico en el derecho penal y la Filosofía del derecho. En sus Obras escogidas: una crítica al derecho tradicional es posible reconocer los principales lineamientos de su doctrina vinculados estrechamente a la influencia del marxismo en su relación con el cristianismo y la necesidad de justificar cambios políticos profundos en esa época en Chile. En efecto, el análisis jurídico de NovOA parte de una constatación de la realidad chilena: «La subsistencia de enormes diferencias en la distribución de la riqueza y la existencia de una enorme masa, [...], colocada en posición de franco menoscabo [...]». De esta manera, distingue entre la organización social y el ordenamiento jurídico. La primera no es determinada por el derecho, sino por elementos como la política y la economía; el derecho, como conjunto de normas positivas, se define en su concepto y fines en una relación instrumental con esta realidad. Así, según NovOA será derecho inocuo el que hace subsistir ese tipo de sociedad, y sólo será derecho justo aquel que tiene como objetivo modificar y eliminar dichas diferencias en la distribución de la riqueza y en la calidad de vida de las personas.

Posteriormente, el positivismo jurídico en su versión kelseniana alcanza su momento de mayor influencia en la cátedra de A. BASCuÑán y de A. SQueLLA, quienes a través de su participación activa en la vida académica, intelectual y profesional extienden la influencia de esta forma de pensamiento. A. SQuelLa ha publicado diversos libros que reflejan su trabajo docente y su importante aporte al estudio de la Filosofía del derecho en Chile. Por ejemplo, se destaca entre sus trabajos la tesis publicada con el título Derecho y moral. ¿Tenemos obligación moral de obedecer el derecho?; y sus libros Introducción al derecho, Estudios sobre derechos humanos, positivismo jurídico, democracia y derechos bumanos y Filosofía del derecho. En este último, SQuELla expresa su positivismo jurídico metodológico, que formula de la mano de N. BOBBIO, y asume la unidad del derecho (teoría monista) estableciendo una distinción —-pero no separación - entre el derecho y la moral considerándolos como «órdenes normativos distintos». La recepción del pensamiento de N. BoBBio en Chile se debe a SQuELLA, a quien dedicó la publicación de su libro Norberto Bobbio: Un hombre fiero y justo.

Más avanzado el siglo XX E. BARROS, influido por los trabajos de DwORKIN en su artículo «Reglas y principios en el derecho», y también en su trabajo de doctorado, critica el positivismo y señala: «[...] el enfoque estrictamente lógico tiene sus serias limitaciones, no siempre comprendidas por los teóricos analíticos, demasiado marcados por los objetivos de formular una teoría general o de agotar el concepto de derecho».

Con la llegada de la década de los noventa, periodo protagonizado por el retorno de Chile a la democracia, aparecieron innovadoras corrientes de análisis del derecho. Dichas corrientes se caracterizan por involucrar ciencias y miradas ajenas al análisis tra- 
dicional de la ciencia jurídica. Nos referimos aquí al Análisis económico del derecho, al Análisis feminista del derecho, al Análisis literario del derecho, etc. En sus inicios la adopción de estas nuevas corrientes por el campo doctrinal chileno fue muy pausada, debido a la desconfianza de ingresar al análisis jurídico otras disciplinas ajenas que no comparten los principios básicos de las ciencias jurídicas. No obstante, con el correr del tiempo la academia chilena ha incluido estas corrientes en su análisis, lo que se puede observar en las crecientes publicaciones al respecto y en su mayor presencia en las aulas universitarias. Sin duda la corriente más popular en Chile entre estas nuevas perspectivas ha sido el Análisis económico del derecho, el que no sólo ha irrumpido en la Filosofía del derecho, sino también en los estudios de derecho civil contractual. Por otra parte, una crítica rigurosa al positivismo jurídico puede hallarse en los trabajos de F. ATRIA tales como «Creación y aplicación del derecho: entre el formalismo y escepticismo» y «La ironía del positivismo jurídico». Su libro On Law and Legal Reasoning es, sin duda, una de las aportaciones más lúcidas a la teoría del derecho contemporánea.

En los últimos años los trabajos de J. GARCía Huidobro y C. ORREGo han intentado actualizar el jusnaturalismo e incoroporarlo en el discurso filosófico vigente. En esta línea destaca el libro Razón práctica y derecho natural, en el que GARCíA HUIDOBRO analiza los principales rasgos de la filosofía iusnaturalista de T. DE AQUINO tal como ha sido expuesta más recientemente por el profesor de Oxford, J. FinNIS. A su vez, OrRego en H. L. A. Hart. Abogado del positivismo jurídico, correspondiente a su tesis doctoral, critica los principales lineamientos de la teoría de HART, paradigma del positivismo jurídico en la segunda mitad del siglo Xx. Especialmente analiza la eventual separación conceptual entre moral y derecho y concluye que la referencia a fines y valores es indispensable para la comprensión del derecho positivo, entre ellos, la idea de bien común como elemento constitutivo del mismo.

Por lo que respecta al legado de HART, es importante destacar el trabajo de C. PEÑA, quien en sus diversas publicaciones ha fomentado y revitalizado el espacio de este autor, paradigmático del positivismo jurídico, en la discusión filosófica jurídica chilena de las últimas décadas. Otro tanto cabe decir de su análisis del pensamiento de R. DwORKin y J. RawLS. El estudio de este último y de su obra ha tenido también una gran influencia en Chile y son muy variados los que se han dedicado a estudiar y divulgar sus trabajos, entre ellos, P. RuIZ TAGLE, «La prioridad del derecho sobre el bien en la Teoría de la justicia de John Rawls», y el mismo C. PEÑA en su reciente obra Rawls: el problema de la realidad y la justificación de la filosofía política. De igual manera, la filosofía política y particularmente la versión republicana de la misma ha tenido un impacto muy decisivo en la filosofía del derecho chilena más reciente como puede apreciarse en el libro de R. CRisti y P. Ruiz TAgLe, La República en Chile. Teoría y práctica del constitucionalismo republicano.

\section{MÉXICO}

La filosofía del derecho contemporánea en México, desde mediados de los cuarenta, comenzó a girar en torno a cuatro personalidades, dos de ellas originales y reconocidas internacionalmente, L. RECASÉNS SICHES (1903-1977) y E. GARCíA MÁYNEZ (19081993), y las otras dos, brillantes y más locales, G. HÉCTOR RodríGUez (1910-1988) 
y R. PReCiAdo HeRnÁNDEZ (1908-1991). La influencia de este primer grupo puede prolongarse con alguna fuerza intelectual hasta los primeros años de la década de los setenta, si bien desde principios de los sesenta hay que reconocer que las filosofías que daban cuenta de sus propuestas en el campo jurídico comenzaron a ser rebasadas por otras ideas filosóficas. Por aquellos años la filosofía analítica, por ejemplo, irrumpía en México con gran vitalidad.

RECASÉNS SiCHES, exiliado en México en 1937, desarrolla su prolífica actividad académica en la Universidad Nacional Autónoma de México. A partir del racio-vitalismo de su maestro ORTEGA Y GASSET y en obras como Vida bumana, sociedad y derecho y Tratado general de filosofía del derecho, RECASÉNS estructura una concepción del derecho, que como producto cultural, se entiende como «una forma objetivada de la vida humana», es decir, «un conjunto de significaciones que constituyen reglas para la conducta humana». De igual manera, el derecho debe comprenderse como un conjunto de normas elaboradas para la realización de valores (axiología jurídica), que se integran existencialmente alrededor del principio de dignidad de la persona humana. En una última etapa de su pensamiento y llevando el vitalismo hasta la teoría del discurso racional, RECASÉNS perfila con cierta originalidad, en su libro Experiencia jurídica, naturaleza de la cosa y lógica «razonable», una lógica de la razón vital o lógica de la acción, que distingue claramente de una lógica formal. Con ello, podría alinearse su concepción, con justicia, dentro de las modernas teorías de la argumentación.

E. García MÁyneZ defendió, de la mano de su maestro en Alemania, N. HARTMANN, una axiología objetivista, misma que le sirvió de fundamento para justificar la obligatoriedad o validez de las normas jurídicas. Pero su objetivismo no lo compromete con las tesis iusnaturalistas. Para MÁYNEZ, el derecho natural no es propiamente hablando, derecho. En su libro La definición del derecho. Ensayo de perspectivismo jurídico, ahora bajo la guía de ORTEGA Y GASSET, desarrolló su teoría de los tres círculos. En ella sostiene la idea de que el derecho es susceptible de tener tres definiciones diversas que corresponden a tres perspectivas distintas con respecto a la noción de validez: formal, intrínseca y positiva. Esta división sólo tiene un valor teórico y la reunión de las tres notas en todos y en cada uno de los preceptos que forman un ordenamiento jurídico constituyen el caso límite o ideal de realización de la justicia. En una etapa posterior de su pensamiento, y durante quince años, se dedica a la elaboración de una lógica jurídica desde un enfoque tradicional —Lógica del concepto jurídico, Lógica del juicio jurídico y Lógica del raciocinio jurídico- que finalmente quedó rebasada por las investigaciones que, paralelamente, venían realizando autores como G. H. VON WRIGHT. La propuesta más sistemática y, en cierto sentido, un compendio de su pensamiento jusfilosófico se encuentra en su libro Filosofía del derecho, en el que toma una cierta distancia de su objetivismo inicial — los valores no existen en sí y por sí, sino que existen para alguien-y elabora una teoría del ordenamiento jurídico más autorreferente.

Sobre RECASÉNS SiCHES y GARCíA MÁYNEZ no se puede ignorar la importancia de su producción intelectual, sin embargo — también hay que decirlo— no se preocuparon por formar discípulos o dar continuidad institucional a una escuela de pensamiento. Otro tanto sucede con Preciado HeRnández. Su obra, Lecciones de filosofía del derecho, pionera en el desarrollo del iunaturalismo en México, sigue siendo una de las 
más leídas en las escuelas de derecho y, con seguridad, habrá quien deba a PRECIADO HERNÁNDEZ lo mejor de su formación iusfilosófica, pero tampoco se preocupó en dejar discípulos. Con todo, el desarrollo del pensamiento iusnaturalista encontrará en $\mathrm{M}$. Villoro, A. Gómez Robledo, H. González Uribe y E. GonzÁlez Morfín a sus representantes más distinguidos.

De G. HÉCTOR RodríGUEZ, neokantiano de la línea de MARBURGO, y estudioso y seguidor de STAMMLER y KELSEN, la situación es un tanto distinta. Su obra no ha tenido la trascendencia necesaria para ser valorada, pero su importancia se puede medir en los discípulos o «compañeros de ruta» que dejó. Desde mediados de los sesenta se conforma con más o menos años de diferencia, el grupo de los «neokantianos»: L. AZUARA, F. Vallado Berrón, U. SCHMill, A. Pérez Carrillo y R. TAMAYo y Salmorán, entre otros. Un sello que los caracteriza es su agudo conocimiento y manejo de la obra de H. KELSEN.

Hacia fines de los sesenta, y especialmente a través del trabajo de J. EsQuiveL (1941-1992) —Kelsen y Ross: formalismo y realismo en la teoría del derecho y Racionalidad jurídica, moral y política, obra póstuma en la que se reúne buena parte de su producción intelectual—, se toma contacto con la filosofía analítica que se desarrollaba pujantemente en el Instituto de Investigaciones Filosóficas de la Universidad Nacional Autónoma de México, con gente como L. Villoro, F. SAlmerón y A. Rossi. A través de ellos y del Instituto se conoce la filosofía analítica del derecho argentina en personas como R. Vernengo, E. Bulygin, C. Alchourrón, E. Garzón Valdés y C. SAntiago NINO. Éstos, a su vez, dan a conocer en México a pensadores como A. Ross, H. HART, K. Olivecrona, G. HenriK VON Wright y otros notables iusfilósofos.

Toda la década de los setenta se caracterizó por una intensa productividad iusfilosófica que, lamentablemente, disminuye de manera sensible desde principios de los años ochenta. No es fácil determinar las causas de esta situación. No pocos la atribuyen a la misma crisis económica de 1982, que obligó a la nueva generación a abandonar la docencia y la investigación en aras de mejores oportunidades económicas en el sector público o en el privado. Lo cierto es que, sin exageración, se puede decir que México perdió a toda una generación de iusfilósofos, cuya consecuencia se percibió en los ochenta y que bien podemos prolongar hasta principios de los noventa. Pese a ello, merece ser destacada la perseverancia de algunos iusfilósofos cuyas obras se abrían camino con gran esfuerzo y, por desgracia, sin el acompañamiento crítico necesario de una comunidad iusfilosófica. Tal es el caso de SCHMILL - El sistema de la Constitución mexicana, Lógica y derecho, Reconstrucción pragmática de la teoría del derecho- - y TAMAYO Y SALMORÁN - El derecho y la ciencia del derecho, Introducción al estudio de la Constitución, Elementos para una teoría general del derecho- ya mencionados; y desde el marxismo jurídico y la teoría crítica, con una revisión del pensamiento kelseniano, el trabajo de Ó. CORREAS y la revista Crítica Jurídica fundada en 1983.

Desde principios de los noventa la filosofía jurídica en México se revitaliza intentando recuperar un valioso tiempo perdido, poniéndose al día en los debates contemporáneos y creando espacios de docencia, investigación y publicaciones en diversas universidades del país. Este cambio respondió también a ciertas condiciones políticojurídicas en el país, especialmente por lo que respecta a la actividad y percepción del poder judicial. Una de estas condiciones es el proceso de democratización y las sucesi- 
vas reformas al sistema judicial: 1988 resultó un año bisagra en México por la sospecha de fraude electoral y, al mismo tiempo, la generación de condiciones de competencia política; y por la otra, porque las reformas al Poder Judicial de 1987, implementadas en 1988, ubican a este último en una relación diferente con el poder político, convirtiendo a la Corte en un Tribunal Constitucional. Otra condición objetiva en México es el redimensionamiento del mismo Poder Judicial y el pluralismo político a partir de un cuestionamiento a fondo del principio de división de poderes: de un partido hegemónico - el Partido Revolucionario Institucional (PRI) que gobernó ininterrumpidamente en México desde 1929 hasta el 2000- se pasó a un gobierno dividido en las cámaras que ha favorecido un mayor equilibrio entre los poderes. Pese a estos cambios, hay que insistir en ello, la apertura política no se correspondió con las enormes carencias sociales. Tal como afirma J. WOLDENBERG:

Hubo una transición democrática que nos hizo pasar de un sistema de partido hegemónico a uno equilibrado; de elecciones sin competencia a procesos competidos; de un mundo de la representación monocolor a uno plural; de una Presidencia desbordada a una acotada; de un Congreso subordinado a uno vivo y plural. Fue un cambio político muy importante. Pero lo que al parecer no cambia, y eso desde HuMBOLDT, es que éste es un país absolutamente contrahecho, cruzado por una desigualdad que, a veces y como la propia CEPAL lo dice, impide pensar en construir un «nosotros» inclusivo, porque México es tantos Méxicos marcados por la desigualdad que el sentido de pertenencia a una comunidad nacional se hace complicado ${ }^{12}$.

El impulso de los estudios de filosofía jurídica en México, en un contexto de mayor apertura democrática, se reflejó en cada una de las diversas escuelas jusfilosóficas. La influencia en el ámbito de la filosofía jurídica de corte analítico-normativo, en lo que se ha dado en llamar «rehabilitación de la razón práctica», se vio impulsada — gracias al apoyo decidido de E. GARZÓN VALDÉS y M. ATIENZA- con la creación y desarro1lo, desde 1991, del Seminario «Eduardo García Máynez» sobre Teoría y filosofía del derecho y, al poco tiempo, en 1994, con la fundación de la revista Isonomía. Ambas iniciativas, así como sendas colecciones de libros, contribuyeron a crear un clima de investigación y docencia que ha tenido resultados positivos para la buena marcha de la disciplina. Desde una epistemología jurídica de corte analítico y argumentativo —en contribuciones como las de C. HUERTA, B. BOLAÑos y R. LARA- y desde una teoría de la justicia y de los derechos humanos, en el contexto de un Estado constitucional, democrático y social de derecho, se inscriben los trabajos de R. VÁzQUEZ, A. RENTEría, J. Cárdenas, J. A. Cruz Parcero, M. Carbonell y P. Salazar Ugarte. Con un enfoque constitucional pragmático, a partir una teoría del mercado, los trabajos de P. LARRAÑAGA, y con un interés especial en la filosofía jurídica latinoamericana y el constitucionalismo estadounidense, los aportes de I. FLORES.

El positivismo jurídico, con la guía de J. EsQUIVEL y una rigurosa formación analítica anglosajona, influye decisivamente en una generación cuya obra quedó sellada en los años ochenta, sin una proyección ulterior y que merece una revisión crítica: Á. Rodríguez Tirado, J. García Rebolledo y A. OÑate, entre otros. La continuidad de esta corriente hasta nuestros días es apreciable en los trabajos de J. ORTIZ, M. ${ }^{a}$ I. Pazos, J. Vega y J. Cerdio.

${ }^{12}$ J. Woldenberg, Entrevista en Milenio, México, 19 de julio de 2010. 
Desde el realismo y la teoría crítica del derecho, y en diálogo constante con la antropología y las ciencias sociales, deben destacarse los trabajos de A. AzUELA, A. BERUmen, M. Díaz y Díaz (1956-2001), S. López Ayllón, H. Fix Fierro y K. AnsolabeHERE. El análisis económico del derecho, si bien con poca penetración en los curricula de las facultades de derecho, se ha desarrollado a partir de la obra de A. ROEMER.

Finalmente, en la línea iusnaturalista tradicional escolástica, con aportaciones en el ámbito del derecho internacional, se ubican los trabajos de J. RuIZ DE SANTIAGO; en una versión renovada desde una hermenéutica analógica y pragmática, destacan las investigaciones de M. BEUCHOT y J. SALDAÑA, y, desde un enfoque historicista y los aportes de la filosofía de la liberación, los trabajos de J. DE LA TORRE RANGEL.

\section{PERÚ}

La filosofía del derecho en Perú, durante la primera mitad del siglo Xx, da continuidad al pensamiento jusfilosófico tradicional de corte iusnaturalista, bien sea en su vertiente escolástica o racionalista. A su vez, comienza a desarrollarse las líneas generales del positivismo jurídico, tanto desde el punto de vista formal como sociológico. M. V. VILLARÁN (1873-1958), por ejemplo, en los albores del siglo XX, adoptó inicialmente un punto de vista iusnaturalista pero luego viró hacia el positivismo como se observa de su artículo «Objeto y división de la Jurisprudencia» (1907). Aquí sostiene que es preciso abandonar la filosofía del derecho tradicional y reemplazarla por una consideración sociológica del derecho. La propuesta de M. V. VILLARÁn debe haber hallado una gran acogida, pues en el libro de J. BAUTISTA DE LAVALLE (1887-1970), La crisis contemporánea de la filosofía del derecho (1911), enormemente influido por las ideas del jusfilósofo italiano I. VANNI, a quien LAVALLE tradujo, se operó una reacción inmediata en contra de aquélla. LAVALLE describía la crisis contemporánea de la filosofía del derecho como la incertidumbre existente sobre el objeto de ésta, generada por la pretensión de la sociología del derecho de desplazar y reemplazar a la filosofía del derecho tradicional. El autor sostenía que la filosofía del derecho seguía siendo necesaria como una disciplina de síntesis que, siguiendo las ideas de VANNI, tiene un contenido triple: a) conocer el derecho; $b$ ) conocer cómo se genera y cuál es su historia, $\mathrm{y} c$ ) indagar por el problema de la justicia.

El gran civilista peruano J. LEÓN BARANDIARÁN (1899-1987) comenzó su producción con el curso Lecciones de filosofía del derecho (1929). El autor rechazaba allí tres concepciones de la filosofía del derecho: la que lo concibe como ciencia del derecho, la que lo ve sólo genéticamente y la que lo encara sociológicamente. Para L. BARANDIARÁN la jusfilosofía estudia el derecho como lo que es (punto de vista gnoseológico) y como lo que debe ser (punto de vista deontológico). El derecho es norma reguladora de la actividad humana. Sus elementos constitutivos son cuatro: el sujeto, el objeto, la relación y la pretensión. Su causa final es la justicia cuya característica más ontológica y dinámica es la equidad. En trabajos posteriores, como en sus Lecciones de filosofía del derecho, el autor hizo una presentación del derecho como constando de tres dimensiones.

M. IBERICO RodRíGUez (1892-1974) fue un eminente filósofo y miembro del Poder Judicial peruano. Para él el derecho es, como disciplina de la conducta social de 
los hombres, esencialmente forma, es decir, un modo de existencia independiente en cierta medida de la materia, y que se imprime a ella haciéndola servir a ciertas intenciones o finalidades de la vida. El derecho es en tanto forma pensamiento jurídico que es objeto de una teoría específica, y que da lugar a un estudio lógico. Fue así como el autor escribió en 1944 unos Principios de Lógica Jurídica, en que IBERICO quiso estudiar las formas de ordenación del pensamiento jurídico. Según el autor la teoría del pensamiento jurídico no se correspondía con la Filosofía del derecho, que es mucho más amplia y que no sólo toma en cuenta el derecho como pensamiento sino también como objetivación social y en su fundamento metafísico.

El gran filósofo peruano del derecho es sin duda F. Miró Quesada CANTUARIAS. En el año 1953 redactó su tesis Bases y lineamientos de la lógica jurídica, que luego publicó en 1956 con el título de Principios fundamentales de lógica jurídica. Para él la lógica jurídica es una lógica específica que «debe determinar cuáles son las estructuras aplicables al campo de los conocimientos jurídicos». Pensaba que las normas jurídicas no son proposiciones descriptivas, por lo que en primera instancia no puede aplicárseles ninguna estructura deductiva. La dificultad puede ser sin embargo superada recurriendo al «principio del paralelismo normativo-proposicional», que establece que a toda norma corresponde una proposición (descriptiva) verdadera - aunque no a toda proposición descriptiva verdadera corresponda una norma-. Supuesto este principio, la derivación se cumple mediante un rodeo: se parte de la norma del caso, se determina la proposición jurídica descriptiva que le corresponde, se deriva deductivamente de ella otra proposición jurídica descriptiva y, finalmente, se regresa de ella a la norma que le corresponde. Años después, MiRÓ QUESADA abandonó su propuesta, habida cuenta del desarrollo de la lógica deóntica. En 1988 ha sostenido, en su ponencia «Lógica Jurídica Idiomática», que la norma posee una estructura mucho más compleja de la habitualmente aceptada: no es ni descriptiva, ni tampoco prescriptiva sino descriptivoprescriptiva, por lo que habría que elaborar una nueva lógica híbrida para poder hacer justicia a las deducciones típicamente jurídicas.

Otro de los objetos del interés de MiRÓ QueSADA ha sido el derecho justo —a él se refiere el artículo de este título recogido en su libro Ensayos de filosofía del derecho (1986) y en su gran artículo posterior «Ensayo de una fundamentación racional de la ética». Nos referiremos a este último texto-. Según MiRó QUESADA, el principio de simetría unifica el mundo teórico y el práctico. En el caso del mundo práctico y más en concreto del derecho, para que una norma pueda ser considerada como fundamentada debe ser simétrica. Esto es, que si obliga a $\mathrm{A}$ frente a $\mathrm{B}$, también debe obligar a $\mathrm{B}$ frente a A. No obstante ésta es sólo una condición suficiente de la fundamentación, a ella debe agregarse como condición necesaria que la norma no debe ser arbitraria.

Finalmente, un tercer gran campo de la filosofía del derecho al que MIRÓ QUESADA ha dedicado su interés es el de la interpretación jurídica; aquí ha escrito el libro Ratio interpretando. Ensayo de Hermenéutica Jurídica. Según el autor los tres tipos principales de interpretación son: la deductiva, que corresponde al problema de las contradicciones que surgen entre las normas; la analógica y extensiva, que se emplea para solucionar el problema representado por el hecho de que la experiencia siempre rebasa cualquier sistema conceptual, y la epifasis, que corresponde a las interpretaciones sintáctica, semántica y contextual que se aplica para resolver las dificultades 
generadas por la empiricidad conceptual y la polisemia. Para MiRó QuesADA todos los numerosos tipos de interpretación propuestos por la tradición jurídica anterior se pueden reducir a estos tres tipos básicos.

Otras figuras representativas de la filosofía peruana del derecho son M. AlzAmorA VALDEZ (1909-1993) y C. FernándeZ SESSAREGO. El primero es autor de los libros Introducción a la ciencia del derecho, La filosofía del derecho en el Perú y Filosofía del derecho. Alzamora distinguía entre el estudio científico del derecho, que responde a la pregunta kantiana quid juris: qué ha sido establecido como derecho por un cierto sistema jurídico, y el estudio filosófico del derecho, que se enfrenta a la pregunta quid jus: qué se entiende in genere por derecho. Según el autor el derecho no se sustenta en un sistema de normas, ni tampoco en un conjunto de valores, ni en la conducta humana sino en la dirección esencial de la persona humana hacia aquellas metas que le corresponden en orden a la realización de su fin racional. En cuanto a la justicia es el bien común. Por su parte, Fernández SeSSAREgo, reconocido civilista peruano, formuló tempranamente un planteamiento tridimensional en su tesis Bosquejo para una determinación ontológica del derecho, según la cual el derecho es conducta humana sujeta a normas y que realizan valores. En un trabajo posterior, Derecho y persona, criticaba desde esta perspectiva el formalismo kelseniano o la visión realista y la marxista del derecho como concepciones unidimensionales del mismo.

En el panorama de la Filosofía del derecho que actualmente se practica en el Perú destacan los trabajos de F. De Trazegnies, D. Sobrevilla, D. García Belaunde y L. M. SÁnchez. TRAZegnies ha publicado los libros Posmodernidad y derecho y Pensando insolentemente. Tres perspectivas académicas sobre el derecho, seguidas de otras insolencias jurídicas. En el primer libro, TRAZEGNIES aboga por un posmodernismo que libere a la posmodernidad de sus estrecheces: que reconozca el orden dentro de la diversidad cultural y a ésta dentro del orden, y en el segundo concibe el derecho como una lucha de valores, propuestas e intereses que sólo puede desarrollarse productivamente si se establecen reglas que eviten que esta pugna se convierta en un suicidio colectivo. SOBREVILLA está próximo a la posición de un positivismo incluyente y ha realizado una destacada labor en el análisis histórico-crítico de las ideas jurídicas contemporáneas, como puede apreciarse en su libro La filosofía alemana del derecho actual de orientación racionalista con estudios sobre AlEXY, HABERMAS y HÖFFE. GARCía BELAUNDE ha escrito el libro Conocimiento y derecho. Apuntes para una filosofía del derecho, en el que defiende una visión tridimensional del derecho cercana a la de $\mathrm{M}$. REALE. L. M. SÁnCHEZ, en su libro Después del positivismo, parte de una crítica radical de las insuficiencias del positivismo jurídico desde las propuestas teóricas de ALEXY, ATIENZA y GARZÓN VALDÉS, entre otros autores, para proponer lo que ha denominado una «re-sustantivación del derecho». Finalmente, hay que destacar el trabajo académico y profesional de A. BullaRD para la introducción en el Perú del Análisis económico del derecho.

\section{URUGUAY}

Hasta fines del siglo XIX, la cátedra en Filosofía del derecho pasó por dos grandes orientaciones: el iusnaturalismo laico, espiritualista, y el positivismo evolucionista, en 
su vertiente spenceriana. Durante este periodo, la cátedra asumió un papel fuertemente polémico y se atribuyó un papel rector en la formación de una conciencia nacional. A partir de la consolidación del estado democrático, a comienzos de siglo XX, la Filosofía del derecho se repliega a una labor orientada a servir de apoyo a la formación profesional de abogados y escribanos, adoptando posiciones eclécticas, de compromiso, sincretismo.

Después de una etapa de normalización de la filosofía en general, y jurídica en particular, con las figuras de C. VAZ FerreIRA (1872-1958) y A. M. Grompone (1893-1965), pensador ecléctico, que combinaba influencias positivistas, jusnaturalistas, marxistas y solidaristas, suceden a este último en la cátedra de Filosofía del derecho y Teoría general del derecho los profesores J. L. MORENO (1925-1981) y E. AGUINSKY (19251999). En sus cursos de Teoría general del derecho Moreno se guiaba básicamente por la teoría pura de KELSEN, en la versión típicamente latinoamericana, esto es, a través de la interpretación de GARCÍA MÁYNEZ y RECASÉNS SiCHES, que eran los autores más leídos entonces. Asimismo, Moreno ensaya lo que él pretendía una fundamentación existencialista del derecho, que no deja de ser un nuevo intento de «compromiso» entre la perspectiva formal y la perspectiva realista. Los intereses de AGUINSKY aparecían más cercanos a la fenomenología, sin embargo, su docencia se enmarcaba dentro del tradicional sincretismo de la filosofía jurídica, aunque introduciendo algunos autores más modernos, como BobBIO, REALE y FERNÁNDEZ GaLIANO. Gracias a este espíritu inocuo la cátedra de Filosofía del derecho no fue afectada bajo el periodo de la dictadura (1973-1985), a pesar que sus integrantes eran demócratas, sin compromisos con el pensamiento totalitario del periodo.

Debe señalarse, sin embargo, que el filósofo del derecho más importante de Uruguay y el único con proyección internacional fue J. LLAMBíAS DE AZEVEDO (1907-1972). Sus principales obras fueron editadas en Buenos Aires, con traducciones al inglés, al alemán y al italiano. Fue el primero que acometió investigaciones serias y originales en la materia. Su pensamiento se movía en la línea de la fenomenología, con influencias de HUSSERL, HARTMANN y SCHELER, sin ocultar su inspiración católica.

Le tocará a H. MalHerbe (1927-1999), un discípulo de J. Llambías de Azevedo, iniciar una profunda renovación en la cátedra de Filosofía del derecho, a la que accede en 1993. Su objetivo principal será una crítica de la dogmática jurídica, todavía dominante en los estudios de derecho. Para ello apela a la hermenéutica contemporánea, la dialéctica y la semiótica. De esta manera, por primera vez se escucharán exposiciones sobre Aristóteles, Kant, Heidegger, Gadamer, Viehweg, Perelman, Foucault, Ch. MORRIS, etc. Esta insólita conjunción de pensadores eran explicados con un rigor inusual para el medio uruguayo y en directa conexión con los problemas del derecho. El magisterio de MALHERBE marcó fuertemente a la generación siguiente de docentes integrada, entre otros, por A. CASTRO, L. Meliante, A. ABAD y Ó. SARLO. En la última etapa de su actividad docente se habían incorporado M. VignA, G. BARDAZANO, G. CALviÑo y M. COLlazo.

El año 2001, luego del fallecimiento de MALHERBE, accede a la cátedra por concurso Ó. SARLO. Formado en la tradición kelseniana, SARLO incorpora a sus intereses la hermenéutica gadameriana, la analítica del lenguaje y otros aportes de la teoría contemporánea del positivismo crítico. Sus intereses principales se orientan a la epistemo- 
logía de ciencia jurídica, la metodología de derecho, la teoría de la argumentación y la técnica legislativa.

En el periodo considerado — segunda mitad de siglo XX en adelante- registramos algunos aportes significativos de pensadores no enmarcados en las cátedras de filosofía de derecho. Quizás el principal impulsor de los estudios iusfilosóficos extra-cátedra haya sido el procesalista E. J. COUTURE, quien introdujo en el país los primeros ensayos en materia de lenguaje jurídico y de lógica jurídica. Otros procesalistas siguieron también su ejemplo, como A. Gelsi BidART, inspirado en M. SCHELER y OrTEGA Y GASSET; L. A. VIeRA Ruiz, con influencias de KelSEn, Ross y el marxismo; D. BARRIOS DE ANGELIS, con una sólida formación en la filosofía alemana. Un aporte insólito para nuestro medio lo constituye la tesis de doctorado del sacerdote J. G. BuZzO SARLO, sobre conocimiento del derecho canónico, influido por J. HERVADA.

También cabe registrar algunos aportes de uruguayos radicados en el exterior, en su mayoría exiliados políticos. En la década de los cuarenta cobró cierta notoriedad L. CARNELLI (1887-1960), ya que después de su exilio político (1933) que integró la escuela egológica liderada por C. Cossio en Argentina. Otros profesores uruguayos con actuación destacada en ámbitos académicos del exterior son E. PIACENZA OtAegui, E. P. Haba, J. Sasso, C. Pereda, D. Schwartz.

\section{VENEZUELA}

La Filosofía del derecho en Venezuela, hoy fuertemente enlazada con la Filosofía política y la economía, muestra una evolución general que ha sido estimulada por la actividad desarrollada principalmente en diversos centros académicos, entre los que se cuentan la Universidad Central de Venezuela, la Universidad de Zulia, la Universidad de Carabobo y la Universidad Católica Andrés Bello de Caracas. Tal actividad ha ejercido a lo largo de los años una clara influencia que permite caracterizar un interesante proceso de maduración conceptual y metodológica.

La obra de R. PiZANi (1909-1997), La filosofía del derecho en Venezuela. Exploración crítica para una vocación, publicada en 1934, evidencia en su título y su contenido tanto el interés por esta materia, como la concepción de ensayo cultural que caracteriza el enfoque en esta época. Este trabajo fue muy influyente entre los intelectuales de su tiempo, época en la que Venezuela abandona la dictadura de J. V. Gómez que había cubierto todo el siglo XX hasta ese momento, y miraba con entusiasmo la posibilidad de avanzar en temas que hasta entonces se habían mantenido en la oscuridad, y de explorar una bibliografía novedosa. Años más tarde, PIZANI trazaría también otra importante huella, esta vez con un nuevo rumbo, al publicar su trabajo Reparos a la teoría egológica del derecho, de 1954, que busca documentar su polémica con el filósofo del derecho argentino C. Cossio. Esta influencia prevalecerá por un buen tiempo en la actividad de los filósofos del derecho venezolanos, marcando una clara orientación positivista.

Paralelamente la Universidad Católica Andrés Bello de Caracas acogió el trabajo académico de L. M. Olaso (SJ), que con el tiempo colocaría en el centro del debate filosófico la discusión sobre los derechos humanos, llegando a integrar un grupo numeroso de investigadores con fuerte inclinación por la crítica social. 
Otra influencia que conviene destacar es la que comienza a gestarse en el Instituto de Ciencias Políticas de la Universidad Central de Venezuela con el trabajo de M. GARCÍA PELAYO (1909-1991), y ulteriormente de J. C. REY, quienes incorporaron categorías políticas en su razonamiento, enriqueciendo de esa manera la lectura filosófica con conceptos de análisis del poder, de la legitimidad y de la eficacia de las normas. Una línea análoga será también asumida por la Universidad de Zulia en su Instituto de Filosofía del derecho bajo la dirección de J. M. DELGADO OCANDO. A lo largo de cinco décadas DELGADO OCANDO ha dirigido su actividad de investigación hacia el intento de de construir el entramado institucional en el que consiste el derecho, asumiendo una perspectiva tópica de la Filosofía del derecho. Algunos puntos problemáticos que ha discutido son el de la relatividad axiológica (no hay valores absolutos); el carácter político del valor justicia; el alcance negativo y formal de la democracia y la sigmática, como estudio de las relaciones del signo jurídico con sus referencias sociales. Estos estudios le han llevado a proponer la revisión de los conceptos fundamentales de la producción jurídica judicial y de la teoría de la argumentación de los jueces.

Por su parte, la importante influencia ejercida por la Universidad de Carabobo sobre la evolución de la Filosofía del derecho se hace efectiva en la labor de R. CARRIÓN quien desde el Centro Latinoamericano de Investigaciones Jurídicas y Sociales (CELIJS) no sólo estimuló el uso de herramientas analíticas, sino que realizó una inestimable labor de gerencia académica y editorial, poniendo en contacto a los filósofos locales con la obra y las personas de los más destacados de la Filosofía del derecho latinoamericana. En el campo de la informática y la semiótica del discurso jurídico, CARRIÓN ha orientado su investigación a la descripción de la semiosis de los signos discursivos legislativo (DL) y judicial (DJ). De una manera no dogmática ha incorporado a esta perspectiva los postulados de las semióticas lógica y analítica del lenguaje jurídico, poniendo énfasis en el análisis de la producción del sentido de los DL y DJ en el seno de la vida social, resaltando así la preeminencia de la pragmática en la construcción del sentido de uno y otro discurso.

En las Universidades de Zulia y Rafael Urdaneta de Maracaibo se han desarrollado los trabajos de J. EsPARZA. En su línea de investigación ha buscado trazar un camino metodológico (meta teoría) a partir del análisis formal del enunciado normativo y sus posibilidades deductivas. Se centró originalmente en una lógica del «hacer» basada en una modalidad deóntica, a partir de la cual se definen por derivación la permisión, la prohibición y la indiferencia, asumiendo la tradición modal leibniziana, desarrollada por G. VON WRIGHT. En su trabajo académico trató de marcar claros linderos con la hermenéutica jurídica, aunque últimamente ha intentado trazar las bases de un sistema de deducción difusa como modelo del razonamiento práctico en el derecho. En otra línea de trabajo ha producido reflexiones filosófico-políticas y existenciales sobre el Estado, la sociedad, la libertad y la cultura.

La prolongada y rigurosa actividad académica de R. PÉREZ PERDOMO en varias instituciones nacionales e internacionales es digna de atención. En la Universidad Central y en la Universidad Metropolitana se concentró sobre todo en desarrollos de la teoría de la argumentación, el análisis del papel de los valores en la educación jurídica y la profesión de abogado y en el estudio del funcionamiento del sistema de administración de justicia. En el Instituto de Estudios Superiores de Administración (IESA) su 
eje temático ha girado alrededor de los valores compartidos en la sociedad venezolana y análisis de la corrupción. En su calidad de director académico del Programa Internacional de la Escuela de Derecho de Stanford ha trabajado sobre cultura jurídica de América Latina y derecho comparado. Fue también director científico del Instituto Internacional de Sociología Jurídica en Oñati. En todos los casos ha incorporado a la Filosofía del derecho un enfoque de corte sociológico y de historia social.

Por último, hay que señalar nuevamente en la Universidad Central de Venezuela, esta vez a través del Programa Posdoctoral de Estudios Normativos, bajo la dirección de J. BARRAGÁn. Del mismo modo que el objeto de la Filosofía del derecho se vio en su momento enriquecido por conceptos derivados de la Ciencia Política, la actividad de este Programa Posdoctoral ha incorporado categorías de análisis provenientes de la Teoría de la Decisión Racional, de la Teoría de los Juegos y de la Economía, con la finalidad de lograr un mejor acercamiento a la complejidad que caracteriza este campo de conocimiento. En el Programa Posdoctoral se ha realizado una importante labor de formación —entre los investigadores relacionados con el Programa cabe mencionar a E. C. JIMÉNEZ SANDOVAL y M. Á. LATOUCHE-y de gerencia académica y editorial que ha permitido el sostenido contacto con investigadores como J. HARSANYI y J. GRIFFIN, lo que ha servido como punto de referencia en los debates y asimismo han contribuido a ensanchar los horizontes de las relaciones institucionales. En concreto, el interés fundamental de BARRAGÁN se ha centrado en temas de decisiones públicas, tanto en el terreno del derecho y la economía como en el de las políticas públicas. En ese campo ha analizado los temas de riesgo e incertidumbre utilizando herramientas de la Teoría de la Legislación, de la Economía Institucional, de la Teoría de la Decisión Racional, y en especial de la Teoría de los Juegos. Desde estas perspectivas ha profundizado problemas inherentes a la Ética social y al diseño y desempeño de las instituciones.

\section{BIBLIOGRAFÍA}

Aguiar, F.; BARRAgÁn, J., y LARA, N. (coords.), 2007: Economía, sociedad y teoría de juegos, España: McGraw Hill.

Aguinsky, E., 1971: Fenomenología y ontología jurídica (con prólogo de J. C. SMITH), Buenos Aires: Pannedille.

Alzamora Valdés, M., 1976: Filosofía del derecho, Lima.

Arango, R., 2005: El concepto de derechos sociales fundamentales, Bogotá: Legis Universidad Nacional.

Atria, F., 2001: On Law and Legal Reasoning, Oxford: Hart Publishing.

BARRAGÁN, J., 2009: Estrategias y derecho, México: Miguel Ángel Porrúa-ITAM.

BERnAl Pulido, C., 2009: El neoconstitucionalismo y la normatividad del derecho, Bogotá: Universidad Externado.

CORREAS, Ó., 1998: Sociología del derecho y crítica jurídica, México: Fontamara.

CORTÉs Rodas, F., 2007: Justicia y exclusión, Bogotá: Siglo del Hombre-Universidad de Antioquia.

Cristi, R., y Ruiz Tagle, P., 2008: La República en Chile. Teoría y práctica del constitucionalismo en Chile, Santiago de Chile: LOM Editores.

Cruz Parcero, J. A., 2007: El lenguaje de los derechos, Madrid: Trotta. 
Delgado Ocando, J. M., 1974: Problemas fundamentales de metodología de la ciencia del derecho, Maracaibo, Venezuela: Centro de Estudios de Filosofía del Derecho.

- 2004: Problemas de filosofía del derecho y del Estado, Valencia-Caracas, Venezuela: Vadell Hnos. Editores.

ESQuivel, J., 1996: Racionalidad jurídica, moral y politica (edición a cargo de A. Pérez CARRILLO), México: Fontamara.

Fernández Sessarego, C., 2006: El derecho como libertad (título original: Bosquejo para una determinación ontológica del derecho), Lima: Ara.

GARCÍA HuIDOBRO, J., 1993: Razón práctica y derecho natural, Valparaíso: EDEVAL.

GARCía MÁynez, E., 1968: Positivismo jurídico, realismo sociológico y jusnaturalismo, México: UNAM.

- 1974: Filosofía del derecho, México: Porrúa.

García Villegas, M.; Uprimny, R., y Rodríguez, C., 2006: ¿Justicia para todos? Sistema judicial, derechos sociales y democracia en Colombia, Bogotá: Norma.

Grompone, J. M., 1932: Filosofía de las revoluciones sociales, Biblioteca de Publicaciones Oficiales de la Facultad de Derecho y Ciencias Sociales, Universidad de Montevideo.

HaBA, E. P., 2006: Metodología jurídica irreverente, Dikinson, S. L.

IBERICO, M., 1944: Principios de lógica jurídica, Lima: San Marcos.

LÓPez MedinA, D., 2004: Teoría impura del derecho, Bogotá: Legis, Universidad Nacional.

Llambías De AzeVedo, J., 1940: Eidética y aporética del derecho. Prolegómenos a la filosofía del derecho, Buenos Aires: Espasa-Calpe; 2. ${ }^{a}$ ed. aumentada, 1958.

MalHeRBE, H., Introducción a la ciencia jurídica, tomos I y II, Montevideo: FCU, 1984 y 1987, respectivamente.

Mejía Quintana, O., 2005: Teoría política, democracia radial y filosofía del derecho, Bogotá: Temis.

Millas, J., 1960: Filosofía del derecho, Santiago de Chile: Editorial Universitaria de Santiago.

Miró Quesada, F., 2008: Problemas fundamentales de lógica jurídica, Obras esenciales, t. VIII, Lima: Ricardo Palma.

- 2010: Ensayos sobre filosofía del derecho, obras esenciales, t. VII, Lima: Ricardo Palma.

Nieto ARTETA, L. E., 1942: Lógica, fenomenología y formalismo jurídico, Santa Fe: Imprenta de la Universidad Nacional.

Novoa MonReal, E., 1993: Obras escogidas: una crítica al derecho tradicional, Santiago de Chile: Centro de Estudios Políticos Latinoamericanos.

PEÑA, C., 2008: Rawls: El problema de la realidad y la justificación en la filosofía política, México: Fontamara.

Pérez Carrillo, A., 2003: La derrotabilidad del derecho, México: Fontamara.

PÉrez Perdomo, R., 1990: Las instituciones de la seguridad: cuáles son los problemas, Caracas: Ediciones IESA.

PiZANI, R., 1954: Reparos a la teoría egológica del derecho, Caracas: Eime.

RECASÉNS SiCHES, L., 1971: Experiencia jurídica, naturaleza de la cosa y lógica «razonable», México: Fondo de Cultura Económica-UNAM.

Ruiz Tagle, P., 2002: Derecho, justicia y libertad, México: Fontamara.

SALAS, M., 2007: «Debate sobre la utilidad de la metodología jurídica», en Isonomía, núm. 27, México: ITAM-Fontamara.

SARLO, O. (con G. CAetano et al.), 2010: Técnica legislativa. Teoría, métodos y aspectos políticoinstitucionales, Montevideo: Parlamento del Uruguay/PNUD.

Schmill, U., 2003: Teoría del derecho y del Estado, México: Porrúa. 
Sobrevilla, D., 2008: La filosofía alemana del derecho actual de orientación racionalista, México: Fontamara.

SQuella, A., 1995: Positivismo jurídico, democracia y derechos bumanos, México: Fontamara.

TAMAYO y SALMORÁN, R., 1992: Elementos para una teoría general del derecho, Themis.

VÁzQuEZ, R., 2006: Entre la libertad y la igualdad, Madrid: Trotta.

VILlar BORDA, L., 1991: Kelsen en Colombia, Bogotá: Temis. 